\title{
Urdimento
}

Revista de Estudos em Artes Cênicas

E-ISSN: 2358.6958

\section{Escrita acadêmica performática... Escrita F(r)iccional: Pureza e perigo}

Luciana de Fatima Rocha Pereira de Lyra

\section{Para citar este artigo:}

LYRA, Luciana de Fatima Rocha Pereira. Escrita acadêmica performática... Escrita $F($ r)iccional: Pureza e perigo. Urdimento, Florianópolis, v. 2, n. 38, ago./set. 2020.

DOI: http:/dx.doi.org/10.5965/14145731023820200033

Este artigo passou pelo Plagiarism Detection Software | iThenticate 
Escrita acadêmica performática... Escrita F(r)iccional: Pureza e perigo

Luciana de Fatima Rocha Pereira de Lyra

\begin{abstract}
Resumo
Este artigo discute o modo como transformamos a experiência artística em escrita, alcançando a dimensão performática deste ato liminar (Turner apud Dawsey, 2005). Do atrito entre corpo/escritura sugere o que se intitula artista/pesquisadora(o) de f(r)iç̧ão (Lyra, 2011, p.44), uma espécie de cartógrafa(o) que traça paisagens na relação eu/alteridade, gerando momentos eletrizantes de uma escrita acadêmica $f(r) i c c i o n a l$. Faz-se mister frisar que o texto é calcado nas pesquisas no Núcleo de Antropologia, Performance e Drama (Napedra/2005-2013); nas experiências com a disciplina ministrada pela pesquisadora nos programas de pós-graduações em artes da UERJ, UDESC e UFRN (2017-2019); e na produção de artigos, dissertações e teses elaboradas com o grupo de pesquisa MOTIM - Mito, Rito e Cartografias Feministas nas Artes.
\end{abstract}

Palavras-chave: Escrita acadêmica performática. Escrita F(r)iccional. Artista de $f(r)$ icção.

\title{
Performing academic writing... F(r)ictional writing: purity and danger
}

\begin{abstract}
This article discusses how we transform artistic experience into writing, reaching the performance dimension of this preliminary act (Turner apud Dawsey, 2005). From the friction between body/writing unveiled here, he suggests what he calls an artist/researcher of fiction (Lyra, 2011), a kind of cartographer who traces landscapes in the relationship with the self/otherness, generate electrifying moments of an academic $f(r) i c t i o n a l$ writing. It is necessary to emphasize that the framework of this text is based at the Center for Anthropology, Performance and Drama (Napedra/2005-2013); in the experiences with the subject taught by me in the graduate programs in arts at UERJ, UDESC and UFRN (2017-2019); and finally, in the production of articles, dissertations and theses developed with the research group MOTIM - Myth, Rite and Feminist Cartography in the Arts.
\end{abstract}

Keywords: Performing academic writing. F(r)ictional writing. F(r)iction artist.

\footnotetext{
Atriz, performer, encenadora, diretora, dramaturga e escritora. Professora adjunta do Departamento de Ensino da Arte e Cultura Popular e da Pós-Graduação em Artes da Universidade do Estado do Rio de Janeiro (UERJ). Professora colaboradora em Artes Cênicas no Programa de Pós-Graduação em Artes Cênicas da Universidade Federal do Rio Grande do Norte (UFRN). Docente colaboradora do Programa de Pós-Graduação em Teatro da Universidade do Estado de Santa Catarina (UDESC). Fundadora de seu estúdio de investigação, UNALUNA - PESQUISA E CRIAÇÃO EM ARTE. Sites: www.unaluna.art.br e www.lucianalyra.com.br.
} 
Este sonho foi de uma assombração triste. Havia uma geleia que estava viva. Quais eram os sentimentos da geleia? o silêncio. Viva e silenciosa, a geleia arrastava-se com dificuldade pela mesa, descendo, subindo, vagarosa, sem se derramar. Quem pegava nela? Ninguém tinha coragem. Quando olhei-a, nela vi espelhado meu próprio rosto mexendo-se lento na sua vida. Minha deformação essencial. Deformada sem me derramar. Também eu apenas viva. (Lispector, 1999, p. 402).

... Assim, lendo Clarice, em epígrafe, venho abrindo os portais da minha experiência de estudos acerca da escrita performática na disciplina ministrada nos programas pós graduações em artes da UERJ, UDESC e UFRN, entre 2017 e 2019, como também nos encontros do grupo de pesquisa MOTIM - Mito, rito e cartografias feministas nas Artes (CNPq), que coordeno na Universidade do Estado do Rio de Janeiro, desde 2014. Assim, lançada no pavor ante ao perigo viscoso que é escrever, sensibilizo-me para uma prática livre de escrita acadêmica, assentada no terreno movediço, mas vivo, que é o performativo. Escrever com a boca úmida da coisa viva, chegar perto dos olhos do escuro, arriscar-me a abrir os olhos no sonho da escritura.

No entanto, faz-se mister lembrar que a iniciativa em ministrar a disciplina intitulada Escrita acadêmica performática: pureza e perigo nos programas de pós e a reflexão destes conteúdos nas discussões do grupo MOTIM, surge em desejo, muito antes, entre 2007 e 2010, quando da minha pesquisa de doutoramento ${ }^{2}$ defendida na Unicamp e desenvolvida junto ao Núcleo de Antropologia, Performance e Drama (NAPEDRA), da USP, grupo este que, nas suas investigações, trafega entre os campos da antropologia da performance e das artes da cena.

Foi justamente no trânsito com o campo da antropologia da performance, que em mim, enquanto artista-pesquisadora, acendeu-se a volição de pensar numa escrita acadêmica que desse conta da experiência artística em

\footnotetext{
2 A pesquisa de doutorado em artes da cena defendida pela pesquisadora, em 2011, na UNICAMP, foi desenvolvida entre os campos da antropologia e das artes, tendo como mote a trama, dita artetnográfica, entre artistas da cena e mulheres do distrito de Tejucupapo, na Zona da Mata Norte de Pernambuco. A comunidade tejucupapense é conhecida por produzir a montagem de espetáculo comunitário $A$ Batalha das Heroínas, escrito e dirigido pela líder Luzia Maria da Silva, a partir de episódio histórico, no qual um coletivo de mulheres venceu uma peleja contra soldados holandeses, em 1646, durante a invasão flamenga tem território pernambucano.
} 
retroalimentação com os campos de alteridade, com a vida, desenvolvendo na tese de doutorado uma escrita híbrida nos três capítulos ou movimentos, antecedidas por um prólogo. Uma escrita sob o signo da performance, composta binariamente por uma vontade documental e uma vontade poética-literária, que apreende a investigação por um viés da subjetividade, do subjuntivo do mundo. Este processo combinatório, ou, digamos, alquímico, talvez, à primeira vista, pudesse me afastar da produção de um discurso de cunho estritamente formal, entretanto, exercitou a livrar-me de mim poeticamente, por que dar irrealidade à imagem ligada a uma forte realidade, coloca-nos no alento da poesia.

No trabalho de doutorado, com o sentido de evitar excessos do exibicionismo personalista, mas ao mesmo tempo utilizando-os em favor da pesquisa, dupliqueime em uma espécie de máscara ritual, em Joana: persona-guia dos escritos. Joana, um mito pessoal que me conduziu na produção da investigação do mestrado, entre 2003 e 2005, e que continuou sua jornada no doutorado, transformou-se não só em personagem da performance contígua à tese, mas em meu alterego literário, em protagonista da própria tese romanceada, uma figura que chefiou o exército de memórias, reflexões e articulações teóricas, fabricando uma realidade ficcional, a partir da fricção entre os universos simbólicos dos envolvidos na pesquisa. Uma escrita que ela própria se pretendeu performática, em minhas palavras, $f(r) i c c i o n a l$.

No texto de doutoramento, desvela-se a persona Joana:

A noite já se mostrava inteira em Recife, capital pernambucana. Era uma quinta-feira, por volta das vinte horas, 14 de janeiro de 2010. Haviam-se passado momentos ou cem anos? O instante é feito de minúsculas partículas e Joana queria guardar aquele na caixa de presentes de sua memória. A plateia repleta de crianças, jovens e adultos formava um exército de 250 pessoas prontas a receber Guerreiras no campo cênico de batalha montado sobre uma lona estendida, que amarrotada, mais parecia lama movediça do manguezal. Entre gambiarras armadas acima deste tapete de um cinza rústico, podia-se ver a lua que na ordem natural brilhava soberana, embora seu sorriso minguante anunciasse o fim do ciclo, as horas escuras. Esta seria a última noite de um circuito de guerra travado há quatro anos, quando Joana avançou inquieta em sua pesquisa sobre guerreiras e heroínas atuais e antepassadas, especialmente acerca das mulheres do distrito de Tejucupapo, município de Goiana-PE. O Sítio da Trindade, no bairro de Casa Amarela, fora o local escolhido para a 
última peleja cênica de Guerreiras. Lá, à época da Invasão Holandesa foi erguido um Forte por Matias de Albuquerque, o Forte do Arraial do Bom Jesus, também conhecido como Arraial Velho do Bom Jesus. Lá, a céu aberto e ao som de ruídos urbanos, este Forte, agora soterrado, mantinha-se imponente em essência, ostentando larga extensão de terra, com um mato rasteiro, que deve ter feito o contentamento de cavalos e homens em antigos combates. (Lyra, 2011, p. 55).

Este jogo com a escritura, esta arbitrariedade poética, esta collage de impressões e vivências, esta justaposição de imagens desvelou meu eu-artista, interessada, sobremaneira, no modus de atuação liminar dos brincantes das manifestações do povo, e dos performers na Arte da performance, instância desvelada na dissertação de mestrado e em minhas ações artísticas, desde o ano 2000. A transgressão tempo-espaço e o fluxo lúdico da escrita propuseram na tese um deslocamento do "eu”, para o "eu-persona". Joana, a máscara, o "nãonão-eu”. Um estranhamento de um eu que, no entanto, não se transforma em um "outro", pois segundo Schechner (apud Dawsey, 2005), a condição subjuntiva que envolve a capacidade de ser outro, "não-eu”, também requer um estranhamento de um "eu" vendo-se-sendo visto de outro lugar pelo "outro", como "outro", como "não-não-eu”, o estado característico da performance é assim, a experiência liminar entre o "não-eu" e o "não-não-eu”.

A experiência com a escrita da tese, trouxe à tona a coragem em romper com o formalismo acadêmico e instaurar uma espécie de epidemia discursiva em outras escrituras como: relatórios científicos, artigos e ensaios, tatuando os vestígios da vida, dos campos de outridade na cena e na seara reflexiva da escrita, em processo de interpenetração. Tratando da escrita sob o signo da performance, que em si tem vocação íntima com o que nos acontece, percebi meu movimento e os espectros de meu desejo em inaugurar novos desenhos metodológicos, abordar temáticas interditas e epistemologias marginais, descoladas dos modelos dominantes de conhecimento que demarcam o poderio do pensamento racionalista, patriarcal, branco e heteronormativo.

No fio vermelho de tempo que liga de forma espiralar os anos de 2011 a 2020, elaborei a compreensão que somente conectades com as forças caóticas de vida, 
que contagiam o pensamento-ação, avançamos no exercício aberto de liberdade em quaisquer contexto, incluindo aí o contexto acadêmico tão afeito a um modelo profissional do exercício do pensamento, do saber formal plenamente capaz de articular discursos competentes, mas que muitas vezes se apresentam como desonestos do ponto de vista existencial (Preciosa, 2010).

A escrita acadêmica performática, que chamo de f(r)iccional, apresenta-se em exercício contínuo de liberdade, de autonomia, com fins de emancipação da pesquisadora e do pesquisador das artes na experimentação, na vida, criadora e criador por excelência, saindo de um reduto imposto rumo aos quintais, aos terreiros, aos ancestrais ao campo de alteridade, atritando arte/vida e legitimando os discursos autorais.

É fato que este meu movimento de repensar a escrita no universo acadêmico no campo das artes se filia a debates a respeito. Investigadoras e investigadores em universidades nacionais e estrangeiras vem instaurando germinais reflexões, ocupando-se com a forma dos materiais bibliográficos escritos por estudantes de pós graduações em artes. Muitos fatores têm contribuído para essa iniciática ebulição na seara da academia, o mais importante deles diz respeito à qualidade dos textos produzidos, muitos das vezes descolados dos contextos de pesquisa e fundados em conceituações e retóricas esvaziadas de experiência. Como nos aponta Rosane Preciosa (2010, p.27), são escritos em que:

\footnotetext{
Varrem-se as incertezas, isolam-se as ideias estranhas, inclassificáveis, evita-se qualquer sensação de desamparo. Enxota-se a vida para o outro lado da calçada, procurando neutralizar os percalços que significa viver. Faz-se de tudo para não desalinhar o cotidiano. Encarna-se um tipo de subjetividade de prontidão, incapaz de aderir ao risco de estar vivo e pensar.
}

Percebo que estamos diante de um momento nodal no desenvolvimento da pesquisa em artes. As metodologias construídas por um viés qualitativo e quantitativo enquadram o que é admissível, contudo, não atendem ao grande contingente de pesquisadoras e pesquisadores conduzidos pela práxis, especialmente nas artes, que, acredito, buscam no caminho performático, legitimar a natureza de suas experiências. Evidente que optar pelo caminho da 
floresta da performatividade incorre em desafios, o primeiro deles, a meu ver, é construir um imbricamento entre 'objeto' e 'sujeito' de pesquisa, implodindo com a ideia de distanciamento do que se olha, do que se estuda para imprimir um lugar sentido das coisas que se vive.

$\mathrm{Na}$ tentativa de dialogar com este primeiro desafio, instalo um primeiro exercício que venho desenvolvendo com as experiências na disciplina ministrada nos programas de pós em artes e também no grupo de pesquisa e orientações. A este exercício chamo memorial do desejo, que nada mais é do que um movimento primal de escrita calcado na memória pessoal, na busca de instigar a pesquisadora e o pesquisador a um processo de construção de autoimagem, uma autorreflexão diante da sua própria pesquisa, etnografando biograficamente de onde parte o interesse de investigação, visualizando onde emergem as imagens da pesquisa ao longo de suas vidas.

o memorial não se desvela como um descritivo de histórias de vida, mas como uma forma reflexiva de sentir esta história, fletindo joelhos e olhando para si. Desta maneira, os diários, epístolas, mapas são caminhos credibilizados, incluindo nestes caminhos de escritura toda sorte de imagens advindas de sons, cantos, poesias, artefatos visuais, objetos pessoais que tenham o poder de materializar a memória e provocar a trança de palavras a construir novos sentidos de olhar o mundo e o que se quer pesquisar deste mundo.

Como exemplo de experiência com a escrita do memorial do desejo, podese observar o trecho abaixo produzido por Camila Durães Zerbinatti, doutoranda da UFSC e estudante da disciplina sobre escrita performática, na UDESC:

Não é nada fácil escrever essas cartografias. Não têm sido nada fácil escrever sobre música e sobre mulheres na música, em geral, apesar de ser justamente isso tudo que eu sou também, que eu desejei estudar e viver. Mas essas cartografias (que entendo no plural, porque é numa confusa e múltipla teia de memórias, lados, olhares, vozes, sensações, emoções e relações que elas se descortinam pra mim) são ainda mais difíceis do que aquilo que já anda difícil. Porque elas falam de mim de um jeito que pouca ou nenhuma outra coisa fala. Elas falam de mim a partir de muita coisa que tenho tentado superar, fugir, negar, resolver, esquecer, ultrapassar, esconder, evitar, apagar - de coisas pras quais tenho tentado me ensurdecer, me cegar, me anestesiar na esperança de 
quem sabe não mais ver, nem ouvir nem sentir. Elas falam de mim a partir de pontos de enlouquecedora vergonha -que aprisiona como correntes, algemas, prisões - e de culpas que pesam centenas de toneladas. Elas falam de mim a partir de pontos de dor que nunca param de doer, a partir de feridas abertas que nunca cicatrizam. A partir de febres que não passam, de adoecimentos sem cura. De traumas e memórias que nunca descansam no passado - estão sempre sangrando no presente e aterrorizando qualquer horizonte de futuro. (Zerbinatti, 2018, não publicado).

Também o teor memorial pode ser observado no exercício poético do artigo ${ }^{3}$ produzido pela doutoranda Franciele Aguiar (MOTIM/UDESC), a partir de sua pesquisa acerca da voz e processo de decolonização do imaginário:

No pesadelo grande, um grande silêncio. Eu colocava o ouvido no chão, para saber se ela respirava. Quem sabe um som, bem pequeno, lá no fundo? O coração da terra não se ouvia, ela perdeu o ritmo, ela esqueceu a sua dança. O dia virou noite, a fumaça impregnada no pulmão do mundo. Eles envenenaram a terra e as palavras que diziam à terra. Eles não cantavam, nunca. Eles queriam me ensinar aquela língua nova, da maldição dos números, das cifras. (Aguiar, 2019, não publicado).

Concomitantemente podemos verificar a experiência de memória no fragmento da dissertação de mestrado de Adriana Rolin (MOTIM/UERJ), na discussão acerca da produção cênica e o feminismo negro:

Sinto um despertar de muitas mulheres, mulheres "daqui" de dentro e de "lá" da ancestralidade. Carrego o tempo da terra, a travessia "daqui" e "lá". Sou uma mulher negra e assim como minhas antepassadas, dei sete voltas na árvore do esquecimento, esqueci durante muitos anos de quem sou "eu" e até de qual "eu" posso escolher ser. "A memória do coração é durável e, sem dúvida, [a atriz] pensa com o coração, mas aqui o coração é preponderante. Isso significa que no teatro, mais do que qualquer outro lugar, é no mundo afetivo que [a atriz] deve tomar consciência" (Artaud, 2006, p. 98). O contexto-histórico referenda que o nosso lugar é de subserviência e subjugo, assim como foi minha avó materna. Mulher negra, analfabeta, brasileira, segunda filha de dezesseis

\footnotetext{
${ }^{3}$ O texto completo intitulado Decolonizar para recantar:por uma audição do mundo no jogo com a vozé fruto de uma comunicação apresentada por Franciele Aguiar, em setembro de 2019, da sexta edição dos Encontros Arcanos, evento que acontece anualmente desde 2014 e que mantém vínculo com o GT Mito, Imagem e Cena, da Associação Brasileira de Pesquisa e Pós-Graduação em Artes Cênicas (ABRACE). Organizando suas temáticas a partir das imagens arquetípicas dos arcanos maiores do Tarô de Marselha, o VI Encontros Arcanos foi realizado em Manaus, na Universidade do Estado do Amazonas (UEA), tendo como eixo temático as cartas do Carro e da Justiça. Entrelaçando perspectivas dos estudos do imaginário e da psicologia arquetípica, o encontro - intitulado Movimentos Decoloniais da Cena e o Imaginário Amazônico: o instável caminho do Carro à Justiça - pautou a necessidade de escuta da sabedoria da floresta e dos povos originários que ali resistem.
} 
e seu dever era cuidar da casa e dos irmãos. Ela tentou subverter o sistema, engravidando de seu então namorado, um homem branco, espanhol, filho único de uma mãe-solo, minha bisavó fora amante de homem casado. Arlete, minha avó, sofrera racismo, machismo e múltiplas violências. (Ribeiro, 2012, p. 20).

Ou ainda, somos convidados a ver vestígios de memória na escrita epistolar desenvolvida no texto dissertativo de Karla Martins (MOTIM/UFRN), quando da abordagem de seu mito-guia4 Santa Teresinha de Liseux na experiência de seu mestrado:

Querida Teresa, antes de mais nada, gostaria de te mostrar algumas coisas que escrevi sobre o primeiro encontro e experiência de tê-la de mãos dadas comigo. Para a nossa jornada, preparei, ainda, um pequeno mapa com indicações dos possíveis portais a serem atravessados e convidei alguns mensageiros que poderão nos ajudar ao longo da travessia. Leia, por gentileza, e me diga se concordas: Era janeiro de 1895, quando a Irmã Teresa do Menino Jesus e da Sagrada Face se colocou de joelhos frente à estátua da Virgem Maria e suplicou-lhe que guiasse a sua pena durante a escrita da história de sua alma, que não fosse ela capaz de traçar sequer uma linha que não agradasse a Deus. O pedido para a feitura dos manuscritos autobiográficos veio de sua irmã Paulina, a quem Teresa dedicou o primeiro caderno chamado de "História primaveril de uma florinha branca, escrita por ela mesma e dedicada à reverenda Madre Inês de Jesus" (Jesus, 2002, p. 48). Mal sabia a freirinha que, em 1995, exatos 100 anos depois, os seus escritos chegariam na cidade de Recife, em Pernambuco, e causariam tamanho alvoroço na vida da jovem que escreve estas palavras. (Silva, 2016, p. 9).

Partindo da noção de "espaço autobiográfico", abordado pela historiógrafa feminista Margareth Rago (2014), o memorial do desejo revela a possibilidade prévia de reinventar histórias de si e circunscrever os impulsos subjetivos primeiros das investigações, ajudando-nos a soltar a escrita no sentido das imagens deflagradas pela memória, dando a possibilidade de traduzir pela poesia, pela imagem o inapreensível plantado na vida, na autobiografia, na presença condenada à desaparição. Presença apartada da palavra, mas intrinsecamente a ela vinculada.

Importante dizer que o exercício da escrita do memorial do desejo que é o

${ }^{4}$ O mito-guia é conceito central na prática da Mitodologia em Arte, conjunto de procedimentos ou jogos existenciais para criação performática forjado pela pesquisadora Luciana Lyra e defendido no ano de 2011 (Doutorado em Arte da Cena/UNICAMP). 
disparo para outras investidas de escrita acadêmica performática, f(r)iccional, tem sido estimulado durante as aulas na disciplina e estudos no grupo de pesquisa, primordialmente, por meio de práticas corporais somáticas e jogos que intitulo de existenciais, seguidos de uma escrita automática ${ }^{5}$ aos moldes surrealistas, onde o pré-estabelecido perde espaço para espontaneidade, a ludicidade, articulando consciente e inconsciente, percepção e criação, escrita e performance.

Construir o memorial do desejo como gatilho para se entender enquanto pesquisadora ou pesquisador é perscrutar quem é e onde trafega esta pesquisadora e este pesquisador, com seus impulsos de criação e investigação. Sendo assim, é do corpo, do movimento, de si, que partem as escrituras. Do corpo e de seus atravessamentos de existência são traduzidas a autoria e a pesquisa. Pensando em Moshe Feldenkrais (1997), pesquisador somático, a quem devo muito do que compreendo sobre corpo, é como partir do movimento para a palavra, ao nos reconhecermos corpo através movimento, reconhecemos a palavra que dele eclode. Desta maneira, somos justamente a palavra que produzimos num movimento absolutamente dinâmico e vivo.

É nesse sentido da dinâmica e da abertura para o que pode vir a ser do movimento que aproximo essa escrita acadêmica performática, a escrita f(r)iccional, da ideia de perigo levantada pela antropóloga Mary Douglas (2012) no que tange às culturas, buscando estimular a criação de textos destituídos de ordem e pureza, inextricavelmente articulados com noções de risco e sujidade, uma escrita acadêmica eletrizante, em contínua transformação, afeita a enredos metafóricos, rendida à multiplicidade de leituras e às visões improváveis, sussurrando e envolvendo a textualidade em milhares de matizes.

Ocupando essa posição de risco e abertura aos influxos da vida, a escrita

\footnotetext{
Escrita automática é o processo de produção de material escrito que objetiva evitar os pensamentos conscientes do autor, através do fluxo do inconsciente. É um de escrita criado pelos dadaístas, mais especificamente pelo posterior líder do movimento surrealista André Breton, no ano de 1919. Por meio da escrita automática o eu do poeta se manifestaria livremente de qualquer repressão da consciência e deixaria crescer o poder criador do homem fora de qualquer influxo castrador. Seu propósito é vencer a censura que se exerce sobre o inconsciente, libertando-o através de atos criativos não programados e sem sentido imediato para a consciência, os quais escapam à vontade do autor. (Escrita Automática. In: Wikipédia, a enciclopédia livre. Flórida: Wikipédia Foundation, 2020.

Disponível em: <https://pt.wikipedia.org/w/index.php?title=Escrita_autom\%C3\%A1tica\&oldid=54811344>.

Acesso em: 25 maio 2020.
} 
impura que esconde e mostra a um só tempo, demarca um espaço de resistência à dominação e ao controle das histórias e narrativas, vinculando-se a estratégias pedagógicas de cunho feminista na abordagem da linguagem, ancorada na subjetividade e na relativização dos discursos. Sobre essa ideia, enfatiza bell hooks (2019, p. 232):

[...] proponho que não necessariamente tenhamos de ouvir e conhecer tudo o que é dito, que não precisemos dominar ou conquistar a narrativa como um todo, que possamos conhecer em fragmentos. Proponho que possamos aprender não só com os espaços de fala, mas também com os espaços de silêncio: que, no ato de ouvir pacientemente outra língua possamos subverter a cultura do frenesi e do consumo capitalistas que exigem que todos os desejos sejam satisfeitos imediatamente.

A filiação ao caminho performativo admite que existem experiências e conhecimentos fundamentais que não são compatíveis com uma única forma indutiva de ver e estar no mundo estável e universal, mas que a partir da perspectiva autoral e deste campo pessoal em diálogo com contextos de alteridade sempre moventes, a partir da f(r)icção, se estabelecem múltiplas formas de apreensão e desvelamento das histórias, as diversas vozes, explorando a miríade de relações entre elas e provocando um topos fértil fundado no entrelugar. Esta fertilização é justamente gerada pela simultaneamente dos discursos, pelas linhas e as entrelinhas, pelo adjacente e o subjacente, pela cena e pela obscena, fazendo submergir subtextos e margens destampados através das palavras inconclusivas. Mais uma vez bell hooks nos convoca: Tomamos a linguagem do opressor e voltamo-la contra si mesma. Fazemos das palavras uma fala contrahegemônica, libertando-nos por meio da língua (2019, p. 233).

Entendo dessa forma, que a pessoalidade desvelada neste processo de escrita ultrapassa o determinismo social que tende a configurar e simbolizar a identidade, o comportamento e os discursos, gestando novas formas de resistir à nomenclatura paralisante do único e do estável. Olhando-nos e pensando de onde partem nossos desejos, encorajamo-nos por transformar as nossas experiências de forma a disponibilizá-las para que outras pessoas possam ver-se espelhadas e se sintam acirradas a descobrirem, elas próprias, suas vidas e seus impulsos de 
criação. Observamos o que criamos na parceria com os outros, não com o intuito primal de encontrarmos lacunas, mas para compartilharmos o surgimento de outras possíveis interpretações da experiência humana e...

Neste momento farto-me do que tanto digo sobre a escrita acadêmica performática, sou impelida a parar. Respiro. Volto à Clarice, desvio minha escrita e percorro o quarto que habito, e como Lispector vejo nele os contornos firmes, sim, endureci a geleia viva em parede. Não aceito. Fecho os olhos e dentro perscruto o escuro, ele me espia com dois olhos grandes e separados. Acho que ao escuro prefiro, nele me ancoro e vejo luzes dentro, palavras em folhas soltas e livros. Mergulho. No escuro, as palavras espessas e pegajosas novamente voltam, vivas como a geleia viva, reencontro-a e a ela me misturo, sou eu mesma viscosa a explorar movimentos e metáforas da dinâmica do conhecimento, do mundo. Volto a escrever, agora por dentro, e por fora, agora, não há mais nada a dizer.

\section{Referências}

AGUIAR, Franciele. Descolonizar para reencantar: por uma audição do mundo no jogo com a voz. Texto produzido a partir de comunicação oral no VI Encontros Arcanos: Movimentos Decoloniais da Cena e o Imaginário Amazônico: o instável caminho do Carro à Justiça. Manaus: Universidade do Estado de Manaus, 2019. Não publicado.

BACHELARD, Gaston. A água e os sonhos: ensaio sobre a imaginação da matéria. São Paulo: Martins Fontes, 1996.

DAWSEY, John. Victor Turner e a Antropologia da Experiência. São Paulo: USP, 2005.

DOUGLAS, Mary. Pureza e perigo. São Paulo: Editora perspectiva, 2012.

FELDENKRAIS, Moshe. Consciência pelo movimento. São Paulo: Summus editorial, 1997.

hooks, Bell. Ensinando a transgredir. a educação como prática de liberdade. São Paulo: Editora Martins Fontes, 2019.

LISPECTOR, Clarice. A descoberta do mundo. Rio de Janeiro: Nova Fronteira, 1984. 
LYRA, Luciana de Fátima Rocha Pereira de. Guerreiras e Heroínas em Performance: Da Artetnografia à Mitodologia em Artes Cênicas. 2011. 533 f. Tese (Doutorado em Artes). Universidade Estadual de Campinas, Campinas, SP.

PRECIOSA, Rosane. Rumores discretos da subjetividade: Sujeito e escritura em processo. Porto Alegre, Editora da UFRGS, 2010.

RAGO, Margareth. A Aventura de Contar-se: Feminismos, Escrita de Si e Invenções de Subjetividades. Campinas: Ed. Unicamp, 2014.

RIBEIRO, Adriana Rolin Lopes Oliveira. Yriádobá da Ira à Flor. Influxos Artaudianos via Mitodologia em Arte. 2019. Dissertação (Mestrado em Artes). Universidade do Estado do Rio de Janeiro, Rio de Janeiro, RJ.

SILVA, Karla Lidiane Costa Martins. Thérese, êxtase de um corpo ofertado: trajeto mitodológico de uma artista de f(r)icção. 2016. Dissertação (Mestrado em Artes Cênicas). Universidade Federal do Rio Grande do Norte, Natal.

ZERBINATTI, Camila Durães. Memorial para a disciplina Escrita Acadêmica e Performática: Pureza e Perigo. Florianópolis: Universidade do Estado de Santa Catarina, 2018. Não publicado.

Recebido em: 16/05/2020

Aprovado em: 16/05/2020 